\title{
Correction to: On the Effects of the Rejuvenation Treatment on Mechanical and Microstructural Properties of IN-738 Superalloy
}

Cosimo Monti, Alessandro Giorgetti, Leonardo Tognarelli, and Francesco Mastromatteo

(published online July 26, 2018)

\section{Correction to:}

JMEPEG (2017) 26(5):2244-2256

https://doi.org/10.1007/s11665-017-2646-2

Readers should note the following error in the first sentence of Abstract for this article: "IN-38" should be "IN-738",

The original article can be found online at https://doi.org/10.1007/ s11665-017-2646-2.

Cosimo Monti and Alessandro Giorgetti, Department of Innovation and Information Engineering, Guglielmo Marconi University, Plinio Street, 44, 00193 Rome, Italy; and Leonardo Tognarelli and Francesco Mastromatteo, Nuovo Pignone Tecnologie SRL, GE Oil \& Gas, F. Matteucci Street, 2, 50127 Florence, Italy. Contact e-mails: c.monti@unimarconi.it, a.giorgetti@unimarconi.it, Leonardo.Tognarelli@ge.com, and francesco.mastromatteo@ge.com. 